\title{
Analysis of Demand Side Response potential in energy clusters
}

\author{
Andrzej Manujlo ${ }^{1, *}$, and Mariusz Kaleta ${ }^{1}$ \\ ${ }^{1}$ Warsaw University of Technology, Institute of Control and Computation Engineering, Poland
}

\begin{abstract}
The paper analyses the possibilities of Demand Side Response (DSR) applications from the point of view of an electricity power cluster. Three possible scenarios for DSR mechanisms that facilitate balancing the cluster in short horizon were formulated. Two scenarios include shifting a part of demand that creates unplanned balancing energy in the cluster. In the first scenario, the unplanned balancing energy is moved to hours with lower prices on the Balancing Market (BM), while in second scenarios we assume that this energy is bought on the competitive market. The third scenario concerns mitigation of investment cost for local distributed resources (DERs) due to DSR program. We present an analysis of monetary savings that has been carried out for exemplary clusters in Polish electrical energy system and based on Polish Balancing Market and Power Exchange data. Although the potential savings per household are too small to create strong incentives for DSR, this amount of money could be notable for the local community as a whole. There is also a big opportunity for increasing the benefits resulting from DSR in case of perceived stronger differentiation of unbalanced prices on $\mathrm{BM}$ as well as strong trend for price increase. We believe that presented results may play an important role to draw the potential development directions for national power clusters.
\end{abstract}

\section{Introduction}

Currently, the power industry exercises radical changes which result in formation of completely new challenges in the field of power system operation and management. One of the key issues that modern power systems are facing is a power balancing under the increasing variability in generation, conditioned by the growing number of renewable sources [1]. The observed transformation constitutes not only challenges, but primarily new possibilities and chances. Solution for the problems which concern the increasing difficulty in terms of balancing the system is in transforming the system and implementing solutions for distributed balancing.

The concept of power clusters, as self-balancing areas, is one of the most important directions of the currently conducted research and legislative efforts. However, achieving a high level of cluster's self-balance requires taking advantage of the distributed resources operating in its area in the best possible manner. This concerns especially consumers and prosumers with a regulatory potential. That is why Demand Side Response (DSR)

*Coresponding author: andrzej.manujlo@pw.edu.pl 
mechanisms seems to be mandatory for efficient development and maintaining the power engineering system in the light of aforementioned transformation [2].

Projects related to the demand side response mechanism were carried out across the globe. LINEAR (Local Intelligent Networks and Energy Active Regions) is a project funded by Instituut voor Wetenschap en Technologie (IWT) in Belgium [3]. It aims at realizing an implementation for automated DSR by means of a pilot and to evaluate the technology, economical value and consumer acceptance. The researchers have proved that process automation is important and has obtained a reduction of over a dozen percent.

In Poland, the energy operator, TAURON, carried out a pilot project of the demand side response mechanism [4]. A reduction of $6 \%$ was achieved. The result could be significantly better if the solutions to be applied required less user input. Notifications about the need for reduction were implemented via SMS. The user received a notification with a certain advance (various time advance variants were tested).

The aim of this paper is to define possible scenarios of DSR usage in order to diminish or avoid the cluster unbalance and to estimate potential money in such DSR programs. The results can give some clues for already operating clusters which currently almost do not take advantage of DSR as well as the number of clusters that are foreseen to be created in the nearest future.

\section{Formulation of DSR usage scenarios}

According to Polish legislation [5] an energy cluster is supposed to striving for selfbalance of energy consumed and produced in the area of cluster. However, currently due to lack of efficient tools for balancing, the final balance of a cluster must be achieved with a help of centralized Balancing Market mechanism. The difference between the planned energy and real consumption or production is called unplanned energy. This part of energy is bought from or sold to Balancing Market, and therefore called balancing unplanned energy, at settlement price of deviation from planned working points, denoted as $C R O$. The intention was that the price CRO should be unfavorable which pushes market participant to minimize deviations from planned energy. However, the relationship between CRO and energy price at Power Exchange are not always so clear.

Since the unbalanced energy generally produces some cost, the natural question immediately arises: how can DSR help in reduction of costs related to imbalance energy. Below we formulate three scenarios for DSR that let a cluster manage their unbalanced energy better in order to reduce cost of balancing.

Scenario 1. Shift of unplanned balancing energy

In this scenario we assume that if the demand is higher than expected one, which creates unbalanced energy, it can be partially postponed and realized in the future. Such shift makes sense if during the next hours the CRO price decreases, so unbalanced energy that is to be bought from Balancing Market is less expensive. We need to note that not every consumer and not within the full range of consumption is willing to shift his or her consumption. Also the distance between moment of original occurrence of demand and time period in which it was actually realized cannot be greater than some reasonable assumed value.

Scenario 2. Conversion of unplanned balancing energy

In this scenario, as well as in scenario 1, we assume that part of demand that is responsible of imbalance is postponed. However, in this case we also assume that due to the demand shift, it is possible to satisfy this part of the demand by buying additional energy at the market. The shift is required to make the transaction possible. Therefore, due to DSR mechanism an unplanned balancing energy is being converted into planned energy.

Scenario 3. Investment avoiding 
The Demand Side Response mechanism allows reduction of peak power, that means it is not needed to build new power plant only to cover peak energy, which occurs fairly. It still necessarily to have some additional production capacities to be used at critical moments, however, it is not required such large extra production capabilities.

\section{Input data and tools}

To analyse formulated scenarios and test them against cost reduction, we prepared data for Polish power system (KSE) [6] and for seven exemplary districts in Poland. Data from the Polish power system website has been collected for 2016 and 2017 years for every hour (17 554 samples of specified data):

- $E_{h}^{K S E}$ - total energy consumption in KSE and hour $h$,

- $E B N O_{h}$ - unplanned balancing energy bought on the balancing market in hour $h$,

- $\mathrm{CRO}_{h}$ - price of unplanned energy on balancing market in hour $h$.

Let us explain that $E B N O_{h}$ is an energy that was not planned in generation and consumption schedules before the time of delivery. Mechanism of BM closes unbalanced positions and particularly settles the energy $E B N O_{h}$ at price $C R O_{h}$, which according to intentions of BM mechanism, should be unfavourable for the consumers.

We also calculated total yearly consumption in KSE, denoted by $E_{\text {year }}^{K S E}$, as a sum of $E_{h}^{K S E}$ for each hour $h$ in 2017 year.

Those data have been automatically retrieved from the website [7] with use of the Selenium library for python language [6]. For effective workflow with big data the jupyter notebook with python and several additional libraries (including numpy, pandas, scipy, matplotlib) have been used [8].

The districts have been chosen to become representative, with big urban districts excluded. Basic data for each district have been acquired from local government raport [9]. It includes number of residents, number of households, and electricity consumption. To give some general overview for data, let us present data for Lidzbarski District. Lidzbarski District consists of 5 communes, while the Polish law specifies the limit of the size of a cluster to 5 communes or one district [10]. The basic data regarding the district concerned is presented in Table 1.

Table 1. Basic statistical data for Lidzbarski District [9]

\begin{tabular}{|c|c|r|}
\hline Data & Notation & \multicolumn{1}{|c|}{ Value } \\
\hline Number of residents & Plateau effect & 13583 \\
\hline Number of households & $E^{\text {Lidz }}$ & $30.89[\mathrm{GWh}]$ \\
\hline $\begin{array}{c}\text { Yearly electricity } \\
\text { consumption in the district }\end{array}$ & $S^{\text {Lidz }}=\frac{E^{\text {Lidz }}}{E_{\text {year }}^{\text {KSE }}}$ & $0,0177 \%$ \\
\hline $\begin{array}{c}\text { Share of district's } \\
\text { consumption in the Polish } \\
\text { power system }\end{array}$ & \\
\hline
\end{tabular}

For further calculations we assume that households with minimal consumption of energy $E_{h}^{\min }$ in hour $h$, will not be willing to participate in DSR. Therefore, only those households which consume more than $E_{h}^{\min }$ should be considered in our further calculations. To 
estimate number of these households as well as their total consumption we simulated consumption of each individual household. First, we estimated hourly total consumption in the district as following:

$$
E_{h}^{L i d z}=S^{L i d z} \cdot E_{h}^{K S E}
$$

Having $E_{h}^{L i d z}$, we generated gamma distributions for each hour in year 2017 separately with the mean equal to $E_{h}^{L i d z}$. The skewness $(\alpha=0.7, \beta=0.1)$ of the distribution has been set in order to mark households with high instantaneous consumption. Exemplary histogram of households power consumption in a specific hour is shown in Fig. 1.

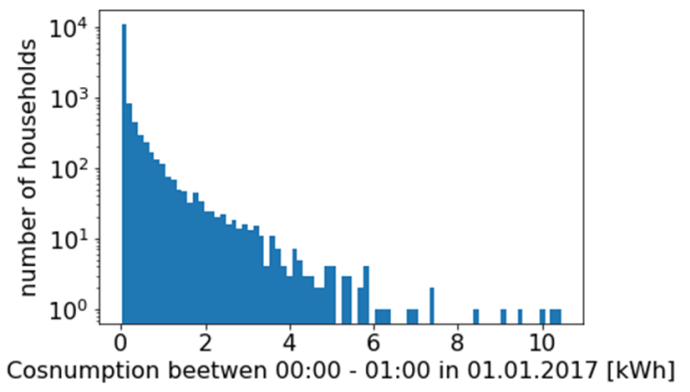

Fig. 1. Distribution of electricity usage in population for specific hour

Further in the paper we assume that only households that consume at least $E_{h}^{\text {Lidz }}=0.1$ $[\mathrm{kW}]$ in a given hour are considered in DSR. Let us denote the set of household satisfying this condition as $H_{h}^{L i d z}$.

Finally, we needed to estimate $E B N O_{h}^{L i d z}$, an unplanned balancing energy for the cluster. We assume that unplanned energy that needs to be bought is proportional to unplanned balancing energy bought from BM in the whole KSE:

$$
E B N O_{h}^{L i d z}=s^{L i d z} \cdot E B N O_{h}
$$

\section{Benefit analysis for defined scenarios}

Implementation of the Demand Side Response (DSR) mechanisms is a big opportunity for a better network stability, reducing purchase of energy and avoiding further investments in new energy sources to cover the demand during peak energy uses [7]. The authors consider three scenarios and shows potential financial benefits resulting from the implementation of the mechanisms. The results have been provided for districts of varied population number. The results for the districts of the size of 100,000 inhabitants have been bolded being the average district size in Poland [10].

\subsection{Shift of unplanned balancing energy}

In this scenario we made a conservative assumption that only $10 \%$ of households participates in DSR. For each hour $h$ such, that $E B N O_{h}^{L i d z}$ is positive, we choose randomly only $10 \%$ of total number of households, however, we choose them only from the set $H_{h}^{L i d z}$ . Let $E_{h}^{H, L i d z}$ be the DSR potential for hour $h$ which is equal to consumption at that hour and 
for selected $10 \%$ of households. Moreover, we assume that selected households are able to participate in DSR within $30 \%$ of their consumption, e.g., $0.3 \cdot E_{h}^{H, L i d z}$. Let us note that in the DSR pilot project with real users in Poland, it appeared that the most active households have reached more than $60 \%$ of average reduction, and sales effectiveness was greater than $50 \%$ for door-to-door channel. Therefore, our assumptions should be considered justified and rather conservative [4].

Finally, we choose the minimum of $E B N O_{h}^{L i d z}$ and $30 \%$ of consumption of selected households. The amount of unplanned energy that can be postponed is calculated as follow:

$$
E_{h}^{D S R}=\min \left(E B N O_{h}^{L i d z} ; 0.3 \cdot E_{h}^{H, L i d z}\right)
$$

We consider different horizons (time windows) within which the consumption can be shifted. For instance, if the size of time window is 1 , it means, that consumption can be only moved to the next hour. Within the given time window we find the lowest settlement price $\mathrm{CRO}$ and we assume, that a household postpones its consumption to this hour. The economic benefit in hour $h$ is defined as follows:

$$
B_{h}^{s 1}=E_{h}^{D S R} \cdot \max _{i=h, . .,(h+W)}\left[C R O_{h}-C R O_{i}\right]
$$

Where $W$ is a size of the window time. Total economic benefit is a sum of hourly benefits. Let us notice that CRO forecasts are being published by TSO and can be used by a household to choose the proper hour, even if the exact forecasted value is fraught with error. If the unplanned energy is already in the cheapest hour, then DSR is not activated at that hour. Similar calculations have been also performed for other 6 districts. Table 2 presents the economic benefits for different time windows from 1 to 24 hours. It is interesting that a plateau effect can be observed in the function of economic benefits on the size of time window.

Fig. 2 illustrates this function for Lidzbarski District. Although the decision on the size of time window depends on individual preferences, it seems that rational time window is about 10 hours. Before the size of 10 , the differneces in savings for the consecutive sizes are greater than 1000, while further increase in size of the window gives only small economic benefits. Also, from a user's point of view a time window larger than 10 hours can be difficult to be accepted, e.g., when setting the laundry using a smart washing machine configured with the DSR mechanism in the power network [11].

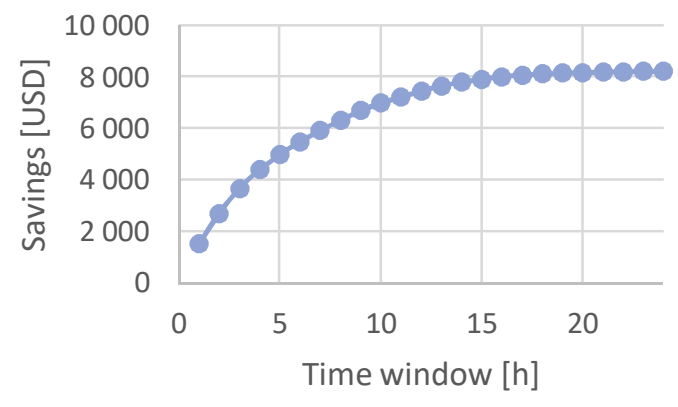

Fig. 2. Economic benefits dependence from size of shift time windows in Lidzbarski District

Assuming 10 hours time window, and 100000 residents as an average size of district in Poland, the estimated potential economic benefit in a district is 16376 USD (see Table 2). It is relatively small amount of the money, especially calculated per one person. Although for individuals these benefits are too small to attract them, it could be enough for the community to make an social impact for their surroundings (i. e. the savings can contribute to 
Participatory Budget). Moreover, taking into account that energy prices are forecasted to rise in the nearest future as well as a stronger diversification in CRO is expected, especially due to the nodal pricing model that is planned to be implemented, the estimated economic benefits may soon become more beneficial also for individuals. Also, assumptions for the behaviour of individuals, may turn out to be too conservative in the future practice.

Table 2. Saving dependence form size of shift time windows in districts of various sizes

\begin{tabular}{|c|c|c|c|c|c|c|c|}
\hline District & Lidzbarski & Sejnowski & Rawicki & Żagański & Kutnowski & Żywiecki & Tarnowski \\
\hline $\begin{array}{c}\text { Number of } \\
\text { residents }\end{array}$ & 42039 & 20417 & 60356 & 80633 & 98583 & 153197 & 200886 \\
\hline $\begin{array}{l}\text { Size of time } \\
\text { window }\end{array}$ & \multicolumn{7}{|c|}{ Potential economic benefits [USD] } \\
\hline 1 & 1535 & 746 & 2204 & 2944 & 3600 & 5594 & 7336 \\
\hline 2 & 2713 & 1317 & 3895 & 5203 & 6361 & 9886 & 12963 \\
\hline 3 & 3682 & 1788 & 5286 & 7062 & 8634 & 13418 & 17594 \\
\hline 4 & 4405 & 2139 & 6324 & 8448 & 10329 & 16051 & 21048 \\
\hline 5 & 4993 & 2425 & 7168 & 9577 & 11708 & 18195 & 23859 \\
\hline 6 & 5485 & 2664 & 7874 & 10520 & 12862 & 19987 & 26208 \\
\hline 7 & 5933 & 2882 & 8519 & 11380 & 13914 & 21622 & 28353 \\
\hline 8 & 6327 & 3073 & 9084 & 12136 & 14838 & 23058 & 30236 \\
\hline 9 & 6694 & 3251 & 9610 & 12839 & 15697 & 24393 & 31987 \\
\hline 10 & 6983 & 3392 & 10026 & 13394 & 16376 & 25448 & 33370 \\
\hline 11 & 7231 & 3512 & 10382 & 13869 & 16957 & 26351 & 34554 \\
\hline 12 & 7462 & 3624 & 10713 & 14312 & 17498 & 27192 & 35657 \\
\hline 13 & 7656 & 3718 & 10992 & 14685 & 17954 & 27901 & 36586 \\
\hline 14 & 7807 & 3792 & 11209 & 14974 & 18308 & 28450 & 37306 \\
\hline 15 & 7918 & 3845 & 11367 & 15186 & 18567 & 28853 & 37835 \\
\hline 16 & 8001 & 3886 & 11487 & 15346 & 18762 & 29156 & 38232 \\
\hline 17 & 8065 & 3917 & 11579 & 15469 & 18913 & 29390 & 38539 \\
\hline 18 & 8116 & 3942 & 11652 & 15566 & 19032 & 29575 & 38781 \\
\hline 19 & 8150 & 3958 & 11702 & 15633 & 19113 & 29701 & 38947 \\
\hline 20 & 8173 & 3970 & 11735 & 15677 & 19167 & 29786 & 39058 \\
\hline 21 & 8189 & 3977 & 11758 & 15708 & 19204 & 29843 & 39133 \\
\hline 22 & 8200 & 3982 & 11773 & 15728 & 19229 & 29882 & 39184 \\
\hline 23 & 8209 & 3987 & 11786 & 15746 & 19251 & 29916 & 39229 \\
\hline 24 & 8222 & 3993 & 11805 & 15770 & 19281 & 29963 & 39290 \\
\hline
\end{tabular}

\subsection{Conversion of unplanned balancing energy}

In the second scenario the benefits resulting from avoidance of unplanned balancing energy in a cluster are considered. Concerning the DSR capabilities we made the same assumptions as in previous scenarios. However, in this scenario we assume that unplanned energy that can be postpone due to DSR mechanism is bought on the market and therefore it is not a unplanned energy no longer. This energy can be bought from local distributed resources, from power exchange or in bilateral contracts. Therefore, due to DSR mechanism, i.e., load shifting, the unplanned balancing energy is converted to the planned energy and cluster unbalance is reduced. To estimate the cost of purchasing the planned energy the average quarterly competitive prices announced by the president of the regulatory office (Urząd Regulacji Energetyki, URE) are applied. Economic benefit in this scenario and hour $h$ is as follows:

$$
B_{h}^{s 2}=E_{h}^{D S R} \cdot \min \left[C R O_{h} ; C_{h}^{U R E}\right]
$$


where $C_{h}^{U R E}$ is the announced competitive price for quarter to which hour $h$ belong to.

The potential economic benefits for different districts are presented in Table 3 . The benefits are similar to those achieved in the first scenario for time window of size 6-7 hours. However, there are additional incentives for energy procurement from local resources. If energy is delivered by local resources, then the flow from transmission system is lower. As a result of this, the cluster incurs lower costs related to the use of transmission system. The variable fee applied in this case is called the quality fee and for the calculations we used 3,44 USD/MWh. Table 4 presents economic benefits obtained thanks to avoiding the quality fee. Total economic benefit, which is sum of results from Table 3 and Table 4, are estimated to 18231 USD in a district with the population of 100000 inhabitants. Such result is unreachable in scenario 1 . However, while in scenario 1 we assumed some window time in which household are able to postpone its consumption, in scenario 2 we just assumed that postponed consumption can be addressed by local generation in reasonable time. Still, comparing these two scenarios it seems that greater potential lies in smoothing demand curve with DSR and more effective usage of local resources instead of gaming on CRO prices.

Table 3. Economic benefits obtained by avoiding the cost of unplanned balancing energy depending on the size of a district

\begin{tabular}{|c|r|r|r|r|r|r|r|}
\hline District & Lidzbarski & Sejnowski & Rawicki & Żagański & Kutnowski & Żywiecki & Tarnowski \\
\hline $\begin{array}{c}\text { Number of } \\
\text { inhabitants }\end{array}$ & 42039 & 20417 & 60356 & 80633 & $\mathbf{9 8 5 8 3}$ & 153197 & 200886 \\
\hline $\begin{array}{c}\text { Potential } \\
\text { savings } \\
\text { [USD] }\end{array}$ & 5824 & 2828 & 8361 & 22999 & 9512 & 11064 & 11867 \\
\hline
\end{tabular}

Table 4. Economic benefits obtained by avoiding the quality fee depending on the size of a district

\begin{tabular}{|c|r|r|r|r|r|r|r|}
\hline District & \multicolumn{1}{|c|}{ Lidzbarski } & \multicolumn{1}{|c|}{ Sejnowski } & Rawicki & Żagański & Kutnowski & Żywiecki & Tarnowski \\
\hline $\begin{array}{c}\text { Number of } \\
\text { Inhabitants }\end{array}$ & 42039 & 20417 & 60356 & 80633 & $\mathbf{9 8 5 5 3}$ & 153197 & 200886 \\
\hline $\begin{array}{c}\text { Potential } \\
\text { savings } \\
\text { [USD] }\end{array}$ & 3718 & 1806 & 5338 & 7132 & $\mathbf{8 7 1 9}$ & 13549 & 17767 \\
\hline
\end{tabular}

\subsection{Avoiding the need for investments in new energy sources due to consumption peaks}

In the third scenario we assume that cluster is striving for self-balancing. It means, that the cluster should include enough generating resources to cover the demand in peak periods. Particularly, having enough generating resources and enough elasticity (reserves) in the cluster would eliminate costs of unplanned energy bought from BM. In this scenario we investigate the economical results of substitution generation capabilities with DSR.

Implementation of the DSR mechanism in a cluster can help to exclude the need for investments made in generating resources in order to cover the demand in peak periods. If the variability of energy consumption is reduced, there will be less generating capacities required in the cluster striving for self-balancing. We collected the investment cost for basic technologies in year 2016 from [12]. Then we calculated the economic benefits assuming different reductions of peak generation. Results are presented in Table 5. For instance, 5\% of reduction factor means that DSR allows for shifting up to $5 \%$ of demand in peak periods. Although, the economic benefits are higher in this scenario, one needs to keep in mind, that this savings can be achieved only once, while benefits in scenario 1 and 2 are periodically. We also assume here, that DSR will have a lasting impact on consumers' behaviour. 
Table 5. Savings in investments for new power sources (for cover peak)

\begin{tabular}{|l|r|r|r|r|r|}
\hline \multicolumn{1}{|c|}{$\begin{array}{c}\text { Type of power } \\
\text { plant }\end{array}$} & \multicolumn{1}{|c|}{$\begin{array}{c}\text { investment cost } \\
\text { [USD/kWh] }\end{array}$} & \multicolumn{4}{|c|}{ Economic benefits for different reduction factors } \\
\hline & & $5 \%$ & $10 \%$ & $15 \%$ & $20 \%$ \\
\hline $\begin{array}{l}\text { Natural Gas turbine } \\
\text { CCGT }\end{array}$ & 1021 & 64470 & 128939 & 193409 & 257879 \\
\hline Biomass + turbine & 4447 & 280800 & 561599 & 842399 & 1123199 \\
\hline Wind & 1841 & 116247 & 232495 & 348742 & 464990 \\
\hline
\end{tabular}

\section{Summary}

The presented calculations show significant economic benefits that can be gathered each year from DSR - demand response mechanism. The profit for a single user is not too great, however, significant amounts can be obtained in the District scale. Every scenario, even simple optimization on CRO prices, reveals its potential, however, we noticed greater benefits when the shifted demand is met by local generation. The greatest economic benefits are related to the possibility of avoiding investments (128939 USD to 842399 USD depending on the type of power plant with $10 \%$ reduction of investment cost). Although this is one-off economic benefit, it can be complementary to previous scenarios, and therefore benefits can accumulate.

The DSR mechanism can operate in two directions: it can allow for consumption reduction when there is power peak demand, but it can also shift the buoyancy to a place where there is too much energy in the network. In the paper only postponing the demand was considered, however, opposite shifts may also generate benefits. This aspect could be introduced as a next step in the research, but assuming rough approximation we can expect further increase of the economic benefits from DSR mechanisms.

Assuming rising energy prices and their volatilities, the gains will become more and more significant and at the same time, the technology enabling the implementation of DSR mechanisms is bound to become cheaper. At some point in time, the decision to implement DSR solutions has the potential to bring measurable financial benefits. It is important to develop appropriate decision support tools that will allow better decision making for effective use of DSR mechanisms.

\section{References}

1. M. Mendonça, S. Lacey, F. Hvelplund, Stability, participation and transparency in renewable energy policy: Lessons from Denmark and the United States, Policy and Society, 27:4 379-398, DOI: 10.1016/j.polsoc.2009.01.007 (2017)

2. K. Kok, Z. Derzsi, J. Gordijn, M. Hommelberg, C. Warmer, R. Kamphuis, H. Akkermans, Agent-based electricity balancing with distributed energy resources, a multiperspective case study. In Hawaii international conference on system sciences, proceedings of the 41 st annual 173-173, IEEE. (2008)

3. R. D'hulst, W. Labeeuw, B. Beusen, S. Claessens, G. Deconinck, K. Vanthournout, Demand response flexibility and flexibility potential of residential smart appliances: Experiences from large pilot test in Belgium. Applied Energy, 155, 79-90 (2015)

4. M. Sobczak et al., "Projekt Smart. Pilotażowe wdrożenie innowacyjnych programów redukcyjnych. Raport końcowy", (Wrocław, Gliwice 2014).

5. The Act of 20 February 2015 on Renewable Energy Sources (2015)

6. R. Lawson, Web scraping with Python. (Packt Publishing Ltd 2015)

7. Website operator Polish Power System - PSE, https://www.pse.pl/ 
8. T. Kluyver, B. Ragan-Kelley, F. Pérez,B.E. Granger, M. Bussonnier, J. Frederic, K. Kelley, J. B. Hamrick, J. Grout, S. Corlay, P. Ivanov, May. Jupyter Notebooks-a publishing format for reproducible computational workflows. In ELPUB 87-90 (2016)

9. A. Koniecko, J. Białuski, H. Uzar, I. Ficek, Strategia ekoenergetyczna powiatu Lidzbarskiego, attachment 1 (2017)

10. Główny Urząd Statystyczny, Roczniki statystyczne Polska w roku 2017, 8-9, (2017)

11. J. Aghaei, M. I. Alizadeh, Demand response in smart electricity grids equipped with renewable energy sources: Renewable and Sustainable Energy, 18, 64-72 (2013)

12. O. Erdinc, Economic impacts of small-scale own generating and storage units, and electric vehicles under different demand response strategies for smart households. Applied Energy, 126, 142-150 (2014)

13. A. Strupczewski, National Center for Nuclear Research, Ocena i analiza kosztów energii elektrycznej z różnych źródeł energii w Polsce, 41 (2016) 